\title{
How Turnover is Effecting Employers in Bangladesh and What Steps Employers are taking to Reduce Turnover in Their Organizations
}

\author{
${ }^{1}$ Abdul Baten, ${ }^{2}$ Ahmed SaadIshtiaque, ${ }^{3}$ Sahadat Hossain \\ ${ }^{1}$ Assistant Professor, ${ }^{2}$ Assistant Professor, ${ }^{3}$ Senior Lecturer, School of Business, \\ University of Liberal Arts Bangladesh
}

\begin{abstract}
Employee turnover is a very critical issue for both employees and the organization they work for. All employers prefer to keep their turnover ratio as low as possible because it is not cost effective when an employee leaves the organization and the company needs to go through the recruitment process all over again to replace that one employee. It is always more expensive for any organization to hire new employees as it requires use of additional financial resources and time. Therefore managers must try to minimize employee's turnover at all costs and find out the causes behind the turnover ratio so as to minimize the reasons for leaving. Some companies perform exit interviews to find out the reasons for turnovers and they try to resolve those issues. Turnover also makes an impact in employees' productivity, moral, corporate culture and employers' reputation. To keep productivity and moral high organizations' needs to keep the turnover low and in addition it spreads good reputation about the company throughout the industry. Job satisfaction of employees can definitely reduce turnover and employers can play a major role in this process. Like other countries Bangladesh also has various factors that affect the cause of employee turnover. As our nation moves into a lower middle income country from its previous low income status, it will need to ensure that it has a healthy workforce with a positive work life balance. This in turn will keep the turnover ratio down to a minimum. As Bangladesh is still in its developing stages, skilled and competent man power is very limited. Therefore it will be very critical for Bangladesh to manage its employee turnover ratio for the private, government and non-government sectors.
\end{abstract}

Keywords-Turnover, Employees, Employers, Productivity, Moral, Reputation, Cost Effectiveness, Job Satisfaction, Economy of Bangladesh, Government and Non-Government Sectors.

\section{INTRODUCTION}

Turnover is a topic of interest for both scholars and practitioners. Exploring the literature on organizational behavior the authors have found that employee turnover is one of the more popular subjects that have been studied in the recent years. To better understand the implications of turnover, one must understand how turnover is defined.

West (2000) depicts an employee's decision to voluntarily leave an organization has important consequences for the individual and the firm, and turnover has been the focus of numerous academic studies (Griffith, 2004). In general employee turnover means number or percentage of workers who leave an organization and are replaced by new employees (Shaw et al. 1998). It is a common practice among employers to measure employee turnover because they want to identify the reasons for employee turnover. Another reason could be because they employers want to identify ways to reduce the cost of hiring new employees. Therefore, managers at all costs must try to minimize employee's turnover and find out the causes behind this incident. Understanding the standard framework of employee's turnover process is huge but there are many factors have been found very efficient in case of explaining employee turnover (Kevin et al. 2004). There are so many factors in Bangladesh that affects the cause of employee turnover. To ensure wealthy economy for a country it's required to have low employee turnover. Same will be applicable for a developing country like Bangladesh where competent man power is very limited. In Bangladesh, it is very important to manage turnover for both government and non-government sectors (Shamsuzzoha et al. 2006). The rate of turnover varies from company to company. Literature indicates that there is a higher level of turnover 
among the private sectors compared to the public sector. This finding would be supportive of Bangladeshi work environment where the public sector enjoys a lot more legal protection than that of the private sector. It was also suggested that the turnover rate can also increase or decrease depending on the region; for instance jobs in Dhaka city may have a higher turnover rate compared to other cities simply because jobs are more readily available in the capital than any other cities. However, to specify the findings we will prefer to perform analysis on some organization/industry wise employee turnover ratio as a sample (Telco, Bank or FMCG) to reflect the overall outcome scenario. So, the purpose of our research is to find out the correlation and influencing factors that may have effect on the relationship between employee satisfaction and turnover attitude in Bangladesh.

\section{Review of Literature}

In Bangladesh, the highest level of turnover normally found in private sectors rather than the public or government sectors. This shows that the rate at which employees switch jobs will vary according to which sector you are in. The highest rates are found where unemployment rate is lower and where it is easy for people to get alternative employment (Rankin, 2006). This indicates that why people switch jobs will also depend on the region they are in. Employee turnover is not always negative. Sometimes employee turnover can create benefits for organization, positively. This might happen when a poor performer is replaced by a more skilled employee and when a retired employee replaced by a younger one (Hoppock, 2005). Employee turnover may also become very costly where hiring new people frequently will shoot up administrative costs, cost of taking someone on a part time basis to fill up for vacancies, cost of training new recruits etc. (Philips, 1990). Most researchers wanted to find out what demographic factors effects the most. But, there has been little consistency in findings the reasons, which is partly due to the diversity of employed and the lack of consistency. High turnover ratio brings both direct and indirect costs (Staw, 1980) found that expenditures of selection, recruitment of new employees, training and development are called direct costs. Dess and Shaw (2001) said, the expenditures of learning, loss of social characteristics are indirect costs. Job satisfaction and turnover are opposite related. Idson \& Feaster (1990) argued that large organizations can provide better chances for advancement for employees by providing higher wages and hence ensure organizational attachment.

A poor relationship with the management can also be an important reason for the employees to leave their jobs. But against his thought Carsten et al. (1987) argued it is comparatively rare for people to leave jobs in which they are happy even though they are offered by higher salary elsewhere. Local unemployment rates also interact with job satisfaction to predict turnover in the effective job market (Trevor, 2001). The conflict between different roles also leads to employees' turnover. This conflict of understanding and act upon the actual role refers to the difference between what people expect of us on the job and what we feel we should do. This causes uncertainty about what our role in a job sector should be. Kahn (1990) mentions that it can be a result of misunderstanding what is expected, how to meet the expectations, or the employee thinking the job should be different (Mishra \& Spreitzer, 1998).

Sometime, an employee gains more skills and he is not compensated for it consequently. As a result, he remains unhappy with the present job description. Price \& Mueller (1986) found that the employee will try to seek desired jobs which will reimburse him at least financially. It is very important for managers and directors to know how many employees are trying to leave their organization and secondly why they want to leave their jobs. These two concerns need to be addressed on a priority basis. From the organizational perspective, they will try their best to hold on to an efficient employee by providing them training and guidance their supervisors best sees fit. But Weisberg, J., \& Kirschenbaum (1993) said new employees deserve more facilitation and support in order to make them familiar with the ups and down of the organization. More attention will not only make them feel welcome in the group, but it will also help guide them to perform their tasks better and contribute more to the organization in the long run.

Employees have a strong need to be informed. Organization having strong communication systems enjoyed lower turnover of employee (Labov, 1997). The positions where employees are involved in some level of the decisionmaking process, they feel comfortable to stay longer in that position. Employees should try to identify factors that may affect their working environment (Manager et al. 1996). However, if there is a shortage of open communication and information sharing within a particular organization, or if employees feel that they are not being empowered

(C) 2019, IJSMS

Page 42 
enough to fulfill the tasks given to them, there is a high chance that the employee will leave sooner than expected. High labor turnover in an organization or in a sector may mean poor personnel policies, poor recruitment policies, poor supervisory practices, poor grievance procedures or lack of motivation. If the factor mentioned are haunting an organization there is a good chance for that organization to be suffering from higher turnover. Usually it means that the organization does not have proper management policies and practices in place when it comes to healing with personnel. It could also mean that the organization is not recruiting their employees in a systematic manner which could give the organization good employees, but places in the wrong positions. Furthermore promotions of employees may not be based on spelled out policies as there is probably no objection procedures in place; and these conditions will provide an unstable and uncertain environment for employees which would force them to quit (Costly et al. 1987).

Employees are is the soul of an organization so turnover of employees is one of the challenging issues of any organization. With turnover of well-trained employees the organization will die. In many factors one is the employee is fitting with the work environment which is the degree of relevancy between the organization and employees. Management of Human Resource department's concern and responsibilities to observe the compatibility of workforce in a business organization (Hatton and Emerson, 1998). Many researchers argue that organizations if not managed properly then high turnover rates might have negative effects on the profitability (Hogan, et al. 1993).

Turnover has many hidden or invisible costs and these hidden costs are result of incoming employees. Co-workers closely associated with incoming employees and position being filled while vacant. On one hand Kemal et al. (2002) said that turnover effects on customer service and satisfaction. But from a different perspective Catherine (2002 argued)that turnover does not affect the customer satisfaction, but rather it brings up certain costs which the companies may not need to face if they can hold on to their employees. These includes costs which occur due to low productivity, there could be loss of potential sales and regular turnovers also increases management time costs as more time has to be given on recruitment processes. If turnover rates are too high it would be difficult to keep these costs at a minimum, which in turn would affect the profitability of the organization. Griffeth et al. (2000) noted that pay and pay-related variables have an unpretentious effect on turnover. Their analysis also included studies that examined the relationship between pay, a person's performance and turnover, while Meaghan et al. (2002) focuses that accessibility of information would lead to strong performance from the employees and creating strong corporate culture. An open door policy would make the information readily available for all employees which would not only make the workers feel that they are appreciated, but it would also make them believe that they are an important part of the organization. This belief would keep the employees motivated towards their individual goals, not only thinking of themselves, but at the same time the positive attitude of the company will make the employees thinking of growing with the organization.

An extensive literature review had revealed that few researches have been conducted related to employee's turnover in Bangladesh as of now. It has also been identified that the owners of most business organizations do not concentrate on the important issue of employee's turnover simply because employees are not aware regarding how frequently employees are switching jobs. They have little idea about how harmful the effect of turnover is into the productivity of their organizations. Production of a manufacturing company can be significantly hampered due to labor turnover as regular dropouts will disrupt the production process. This problem is one of the main factors in the Ready Made Garment (RMG) sectors in Bangladesh. A small percentage of regular turnover may cause considerable amount of production loss due to disruption in the production output. It may take some time before workers are replaced. Even if they are replaced, in most cases experienced workers are being replaced by someone who is fairly new with little or no experience. These workers if changed regularly will need constant supervision and many times even in-house training. These will drive up cost and waste more production time. There is an overall disruption in the production process which in the long run will drive up costs. Turnover directly affects the production and productivity as replacement is costly and time consuming. So many formalities must be maintain to replace a person. Another factor which organizations should be mindful of is replacing efficient employees with older employees hoping that they would come in with experience and will save the company training time and costs. Sometimes the older employee may be slower and less efficient than the younger and less experienced worker. However there is a chance that hiring the older employee may bring in more benefits to the organization where the older employee does have more experience and could be promoted to a higher position sooner than expected. Turnover therefore 
sometimes are considered as being tradeoffs among organizations where one organization may gain more than the other.

Job satisfaction and employees' turnover are inversely proportional. With decrease in the strength of one, there is increase in the strength of the other. Job satisfaction and turnover are negatively related (Griffeth et al., 2000). Another researcher said that future good career and turnover are opposite related (Koh and Goh, 1995). There are many other factors which seem to be the core factors of turnover and job satisfaction according to Price and Mueller (1986) where they have mentioned that providing promotions in due time will motivate the employees to stay longer and reduce the turnover rate. The organization's efficiency also depends on the employee's skill sets and a motivated workforce is going to work more effectively than most. If a skilled person leaves an organization, the results will be very high

where the impact will be less, as in the case of a semi-skilled or non-skilled person.

Employment satisfaction is inversely proportional to employee turnover. The strength of the other is increased with a decline in one's strength. Among job satisfaction and turnover there is a negative relationship (Griffeth et al., 2000). Another researcher said the opposite is related to future successful career and turnover (Koh and Goh, 1995). There are many other factors that seem to be the most important factors of job satisfaction and retention according to Price and Mueller (1986) where they said that promoting in a timely manner would encourage many workers to stay longer with the company, which will increase the rate of turnover of employees. The turnover of the subject workers is widely studied from multiple perspectives and the causes of an employee's turnover in a company are indicated by various factors. It is considered important and critical in this new world of technology and entrepreneurship to equip their workers with the latest market trends. Employee turnover is a serious side that can be managed. Price and Mueller (2001) identified that in order to measure actual turnover, turnover intentions provide an alternative. It was referred to by Cotton and Tuttle (1986) as the estimated probability of an individual staying with an employing organization. If staff finds the work environment to be polite and friendly, they can work with company longer (Moorman, 1991).

High turnover rate is correlated with direct and indirect costs. Staw (1980) states that recruiting new employees from a broad pull and requiring them to go through the recruitment process followed by basic training, as the company needs, are all perceived to be direct costs of having a high turnover. Likewise, training investment, loss of social features, are indirect costs (Dess and Shaw, 2001). Because of the demands on workers, attrition can be likely. It can be described as a willingness to leave the organization consciously and deliberately (Tett and Meyer, 1993). Black and Edwards (2000) said that financial crises play a major role along with the shift in organizational strategy. Such big practices result in a lack of job security and employee turnover because it breaks down the workforce's genuine actions. Employees are the environment's material. So whatever the environmental patterns that the company would follow for Maslow's (1970) smooth operations and desires, and Herzberg's (1973) theories integrated an employee's value to drive an organization. Amabile (1997) identified an employee's need for extrinsic motivation.

Demographic factors are closely related to employee turnover, according to (William and Hazer, 1986). Many hypotheses and views on turnover and its effect on the objective of the company have been identified, but no one has indicated that retirement benefits, job security, and financial crises are the main causes of employee turnover. The best way to ensure that employees do not leave the organization is to ensure that they hire the right employees to start with. Clearly define the position for both the organization and the candidates. And then be sure that the applicant is not only appropriate for it, but also for the culture of the company. As the old saying goes, "a stich saves nine in time." Likewise, if and when it may become necessary, it is also necessary to reduce employee losses. Depending on the situation, some employees may need to be laid off by the organization to reduce costs, so the high turnover rate may not be so bad. Occasionally, even if the company follows the advice above, they get an employee who just doesn't suit, no matter what they're trying to do. So, no matter how effective they might be in their actual work, their culture is bad for an employee who is a bad fit, and that causes cultural debt. By poisoning the company's well, they will do more harm than good. Cut them off. Make sure the businesses are paying workers the fair going salary for their jobs and giving them competitive advantages, which might seem like a no brainer but they would be surprised how few companies offer ups that keep up with the growth of an employee and the actual that price. We are respected and honored to show workers by giving them real-time recognition that recognizes their accomplishments and efforts. Consider it unique, personal, and measurable reward endorsed, and they will also be 
rewarded - with their loyalty. Employees of today are searching for a flexible life or work balance. That has retroactive consequences.

Which means, if they don't give flexibility to workers over working hours and places, they might easily leave the company for someone they want. The organization needs to save most of the resources to function on the basis of the performance, and they need to work throughout the year to build a culture of involvement in the business. Too many execs, joy may sound a little soft and spongy, but the numbers behind it are all but that. Literature suggests that one of the key indicators of job satisfaction is employee happiness. There will be less absenteeism if an employee is satisfied at their job and most employees will readily comply with the corporate values. Investing in employee satisfaction can pay dividends in dedication, efficiency, and retention. Employees put enormous value on growth opportunities.

\section{METHODOLOGY}

Convenience sampling was used to collect survey data using face to face interview on various companies situated in Dhaka city to study the job switching patterns of employees from various age and socio-economic groups.

\section{Problem Statement}

Turnover mainly arises from the unhappiness from job placement for individual employee. But being unhappy in a job is not the only reason why people leave one company for another. If the skills that employees acquire are in demand, they may be lured away by higher pay, better benefits or for a better job growth potential to another organization. Some empirical studies have demonstrated that turnover is associated situations with demographic and biographical characteristics of workers. This proposed paper will emphasize on objectives to find out the relationship between the demographic factors which effects vastly on the employee turnover in Bangladesh.

Purpose of Research

The purpose of this study is to identify if demographic factors such as differences in age, gender, educational background, location etc. affect the overall job satisfaction and rate of turnover of various employees working with small to medium organizations at entry to mid-level positions.

\section{Scope of Research}

This research paper was to evaluate the extent to which constructs from theories of turnover developed in Bangladesh, modified for the local environment, generalize to another culture. There are several types of factors to determine the employee turnover. As like, Social, Cultural and Economic factors. A model based on existing academic research on turnover, the culture of Bangladesh and the results of qualitative interviews was developed. The research emphasizes the impact of various types of satisfaction, including job satisfaction, satisfaction with supervisor and co-worker treatment, and the factors that bind employees to their current employer. Now if anyone wants to find out the political reasons for employee turnover from this research then they cannot find it from here. Because we did not discuss any political reasons here.

\section{Study Hypothesis}

Employee Demographics have moderating role in the relationship between overall Employee Satisfaction and Turnover attitude.

\section{RESULTS}

To better understand the employee behavior when it comes to job switching we need to first understanding the employee profile of the organizations which this study looks into. An overall picture of the average employee will make it easier for top management to understand who their employees are and that in turn can help them develop a better package for their employees so that their turnover ratio will come down to a desirable level. 


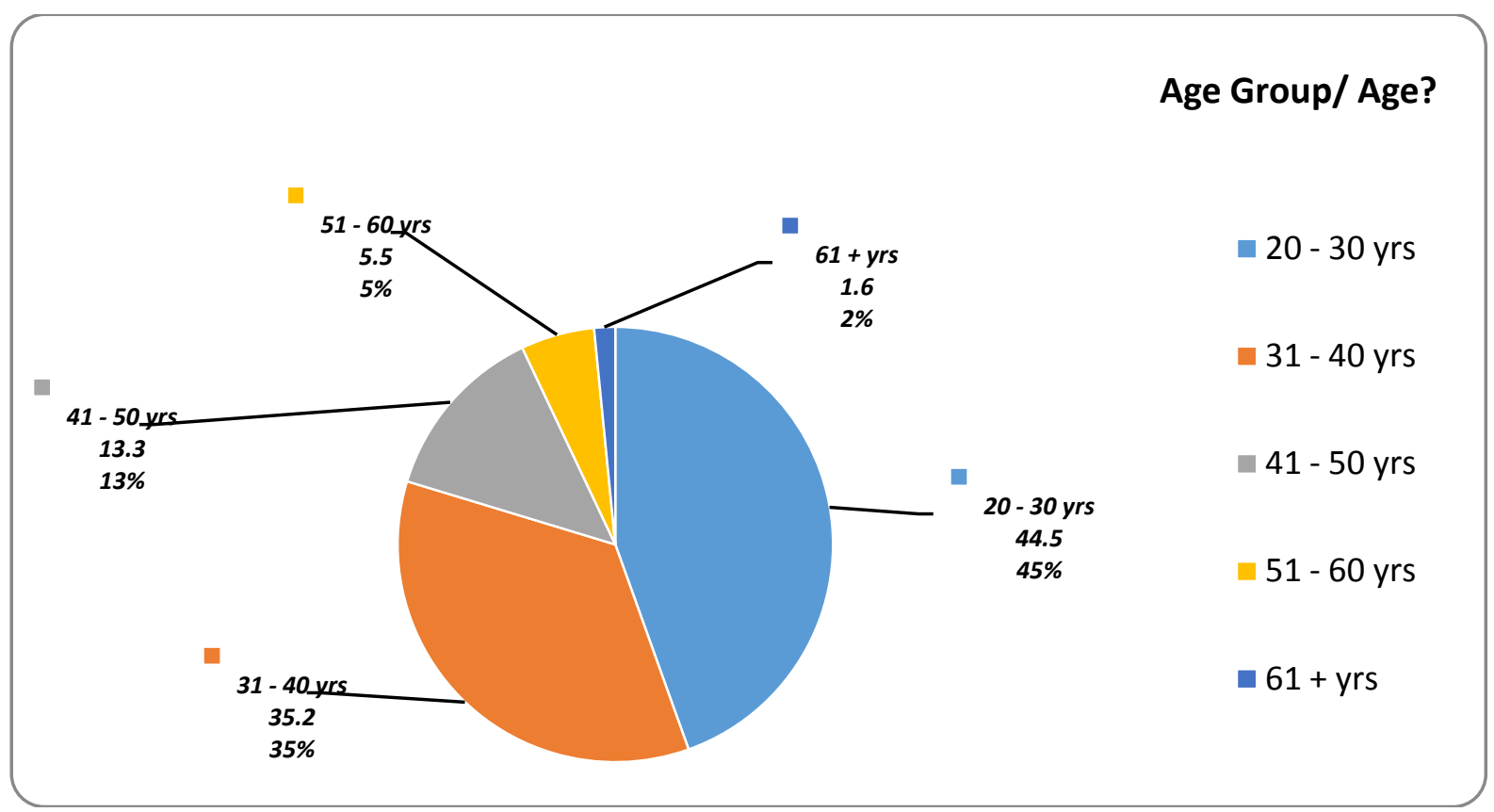

Fig. 1 Age of respondents

Looking at the average age of the employees we find that most of the companies have about half of their employees who are between the age of 20 to 30 which needs to be addressed as historically this is the groups that is quite likely to switch jobs faster than others. The second biggest chunk of employees are between the age of 31 to 40 and although they are comparatively stable, they too can switch jobs as they are more experienced and can be easily attracted by better packages offered by competing firms. The safer groups of employees are in the age bracket of 41 to 50 and above, but that is comprised of only $20 \%$ of the total employee population.

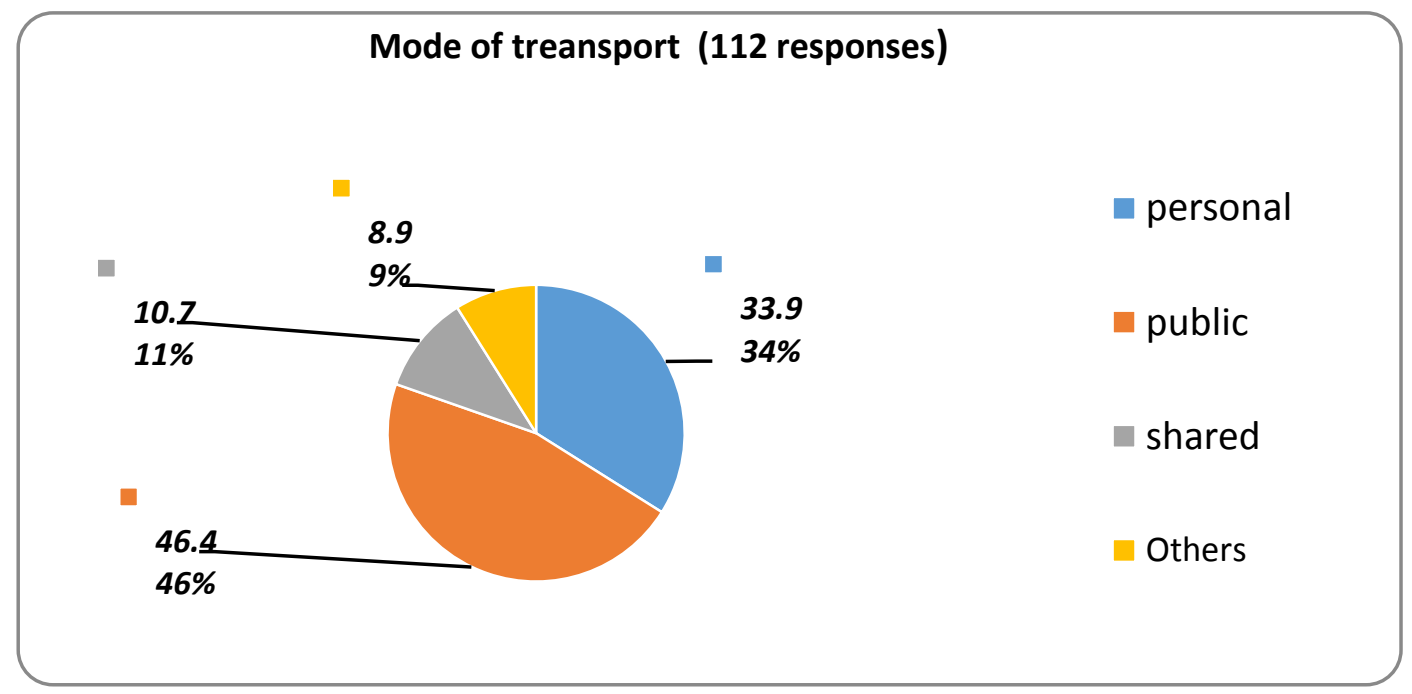

Fig: 2 Transportation used 


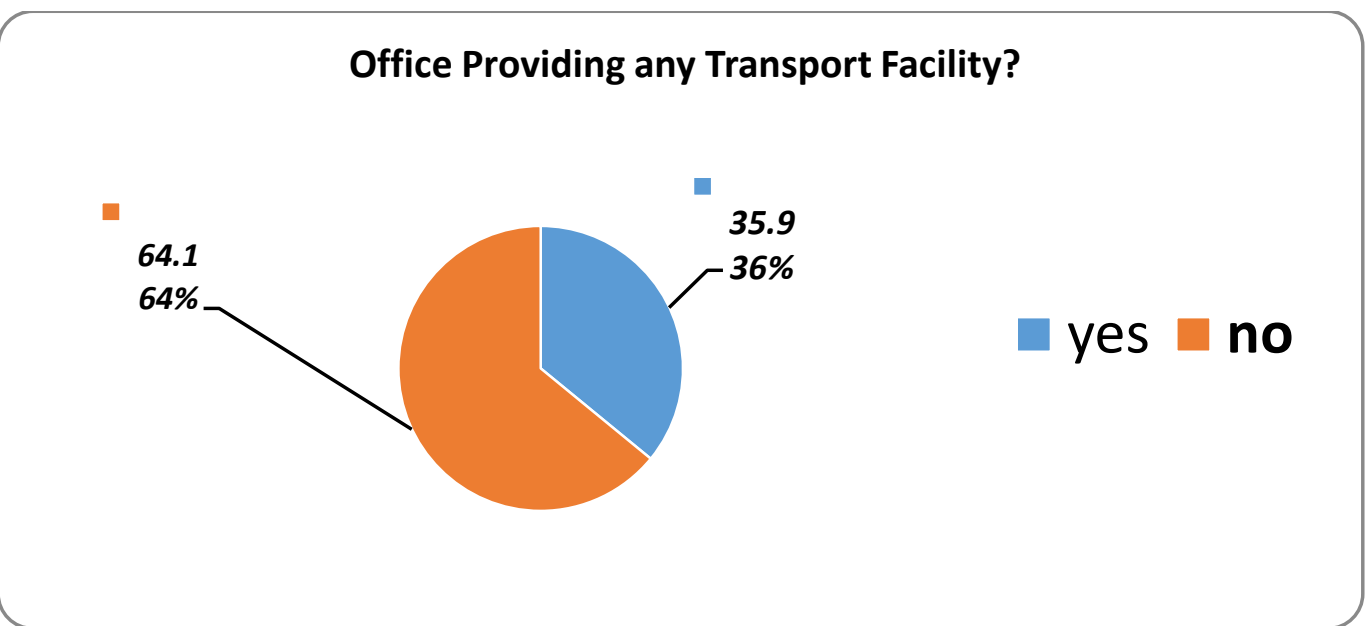

Fig: 3 Office transport

If we look closely at the above mentioned graph we find that majority of the employees of the studied organizations are commuting from home to office using public transport (46\%). If is well established that the public transport system of Dhaka city is incapable of supporting the growing demand and the government funds are not sufficient enough to develop a modern infrastructure to meet the public's demand. Not to mention that the current infrastructure that is available for the public to use is backdated, not maintained properly due to lack of funds, the capacity is inadequate, do not come to time and is dangerously affected by the overall traffic jams that occur daily on the roads. Under these circumstances any transportation support, for instance a company bus service, provided by respective organizations for their mid-level and lower level employees would be greatly appreciated. It could be an effective fringe benefit tool for companies to use to motivate employees to stay with the firm.

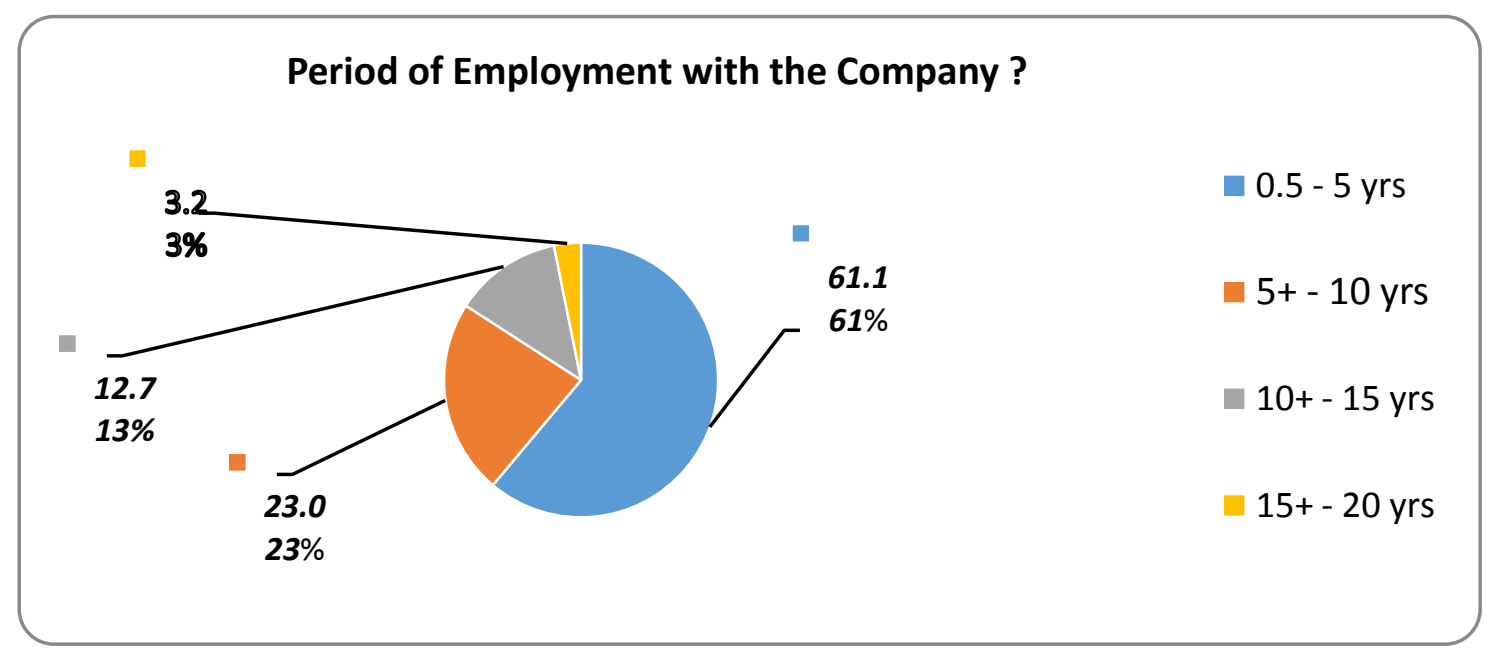

Fig: 4 Year of Experience 


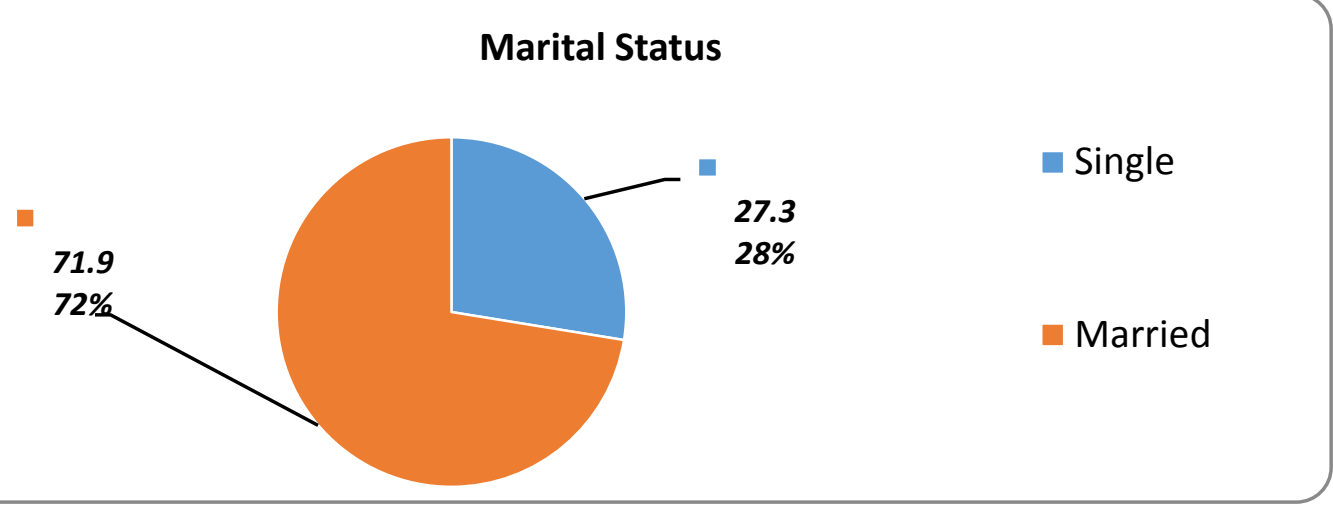

Fig: 5 Marital Statuses

An important factor that needs to be mentioned is that with most firms we find that majority of the employees do not stay with the company for more than 5 years $(61 \%)$. But there is some good news for the companies, which shows that about $23 \%$ of the employees are sticking to a firm for somewhere between 5 to 10 years. This statistic could be improved if we take a close look at the $23 \%$ who are staying and try to provide the same motivation to the younger employees. We also find that most of the employees are already married (72\%) at this stage of their carrier. This is a good number for the firms to work with as they can take the fact that these family men need to have a stable job which provide adequate job satisfaction and a prospect for carrier development which would provide them with more job security and an overall better package. Companies could create $\mathrm{n}$ corporate culture which is family friendly by providing a better work like balance which would attract any employee who are married and needs to give time to the family members. Therefore activities such as annual picnics which involve inviting the entire family could be a start. Life insurance and health insurance policies for the entire family could be lucrative to employees. Strictly maintaining office closing hours could be a great was to promote work like balance. These combined efforts could become an effective non-financial incentive package for the employees this study tries to profile. At a snapshot the employees that should be targeted would be primarily male, young, but married employees, between the ages of 20 to 30, most of whom are using public transport to commute to office every day and holding entry-level to mid-level posts. A well thought out benefit package with a carrier development perspective should be sufficient to reduce employee turnover and increase long term job satisfaction.

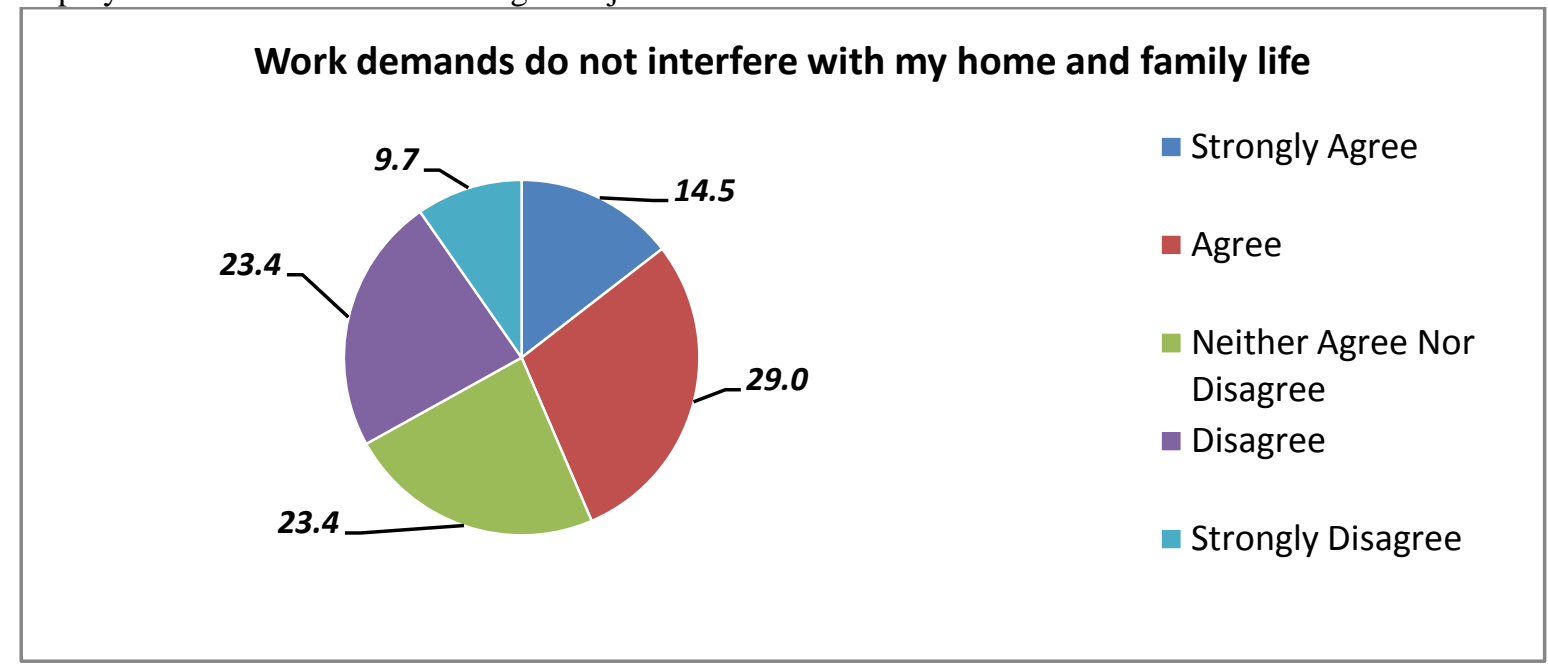

Fig: 6 Work Life Balance 


\title{
My plans for family activities conflict with my work-related duties
}

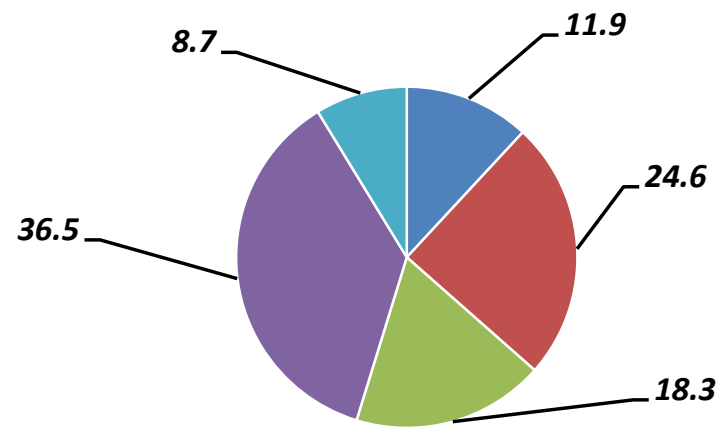

- Strongly Agree

Agree

Neither Agree Nor Disagree

- Disagree

- Strongly Disagree

Fig: 7 Work Life Conflicts

The study asks the respondents if they feel that their current workload interferes with their work life balance. Although a good number of the respondents do not feel that there is a problem with the work life balance (29\%) there is also a good number of respondents (34\%) that feel that they are being overworked and that is taking away time from their families. Many (36\%) of the respondents also feel that their plans with the family are sometimes under conflict with work related deadlines and may have to be postponed or canceled. This leads to unsatisfactory working conditions and could be the cause for many to look for jobs that demand less or more flexible timing.

Current mindset of today's' workers seem to be leaning towards regularly switching jobs in order to find not necessarily a better paid job, but rather a better suited job in terms of flexibility in working hours, better working conditions in terms of not only office decor, esthetics, sufficient lighting etc., but also in terms of having a friendly supervisor to work under and less office polities to deal with in general.

\section{Switching job is essential to be successful in career}

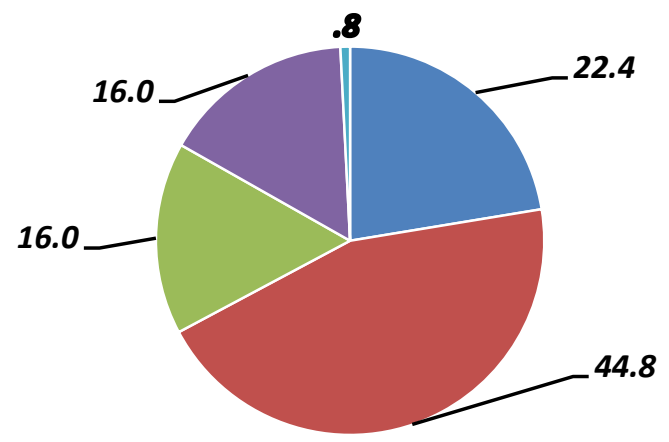

\author{
Strongly Agree \\ Agree \\ Neither Agree Nor \\ Disagree \\ Disagree
}

- Strongly Disagree

Fig: 8 Job Switching Tendencies

Taking a look at the data would suggest that majority $(67 \%)$ of the employees these days genuinely believe that they need to switch their jobs more frequently in order to become successful in the current market. It was also found that about a quarter of the respondents are always doing some sort of an activity which may indicate that they are looking for a job. For example they are either reading the classified ads in the paper, browsing through the job sites in the net, filling up an application, had a job interview or at least has spoken to someone about a job opening such as a previous employee, a current co-worker, friend or family member. 
This is an alarming scenario for organizations because if the corporate culture is to switch frequently than firms will need to give serious through into how to change this mindset as it may become very costly for companies if they need to hire new requites in a regular basis. It will not only waste more resources such as time and finances, but it may also affect the overall performance of employees on any given firm given that they cannot hold on to enough employees with a good number of years under their belt whose experiences always contributes to the overall firm efficiency.

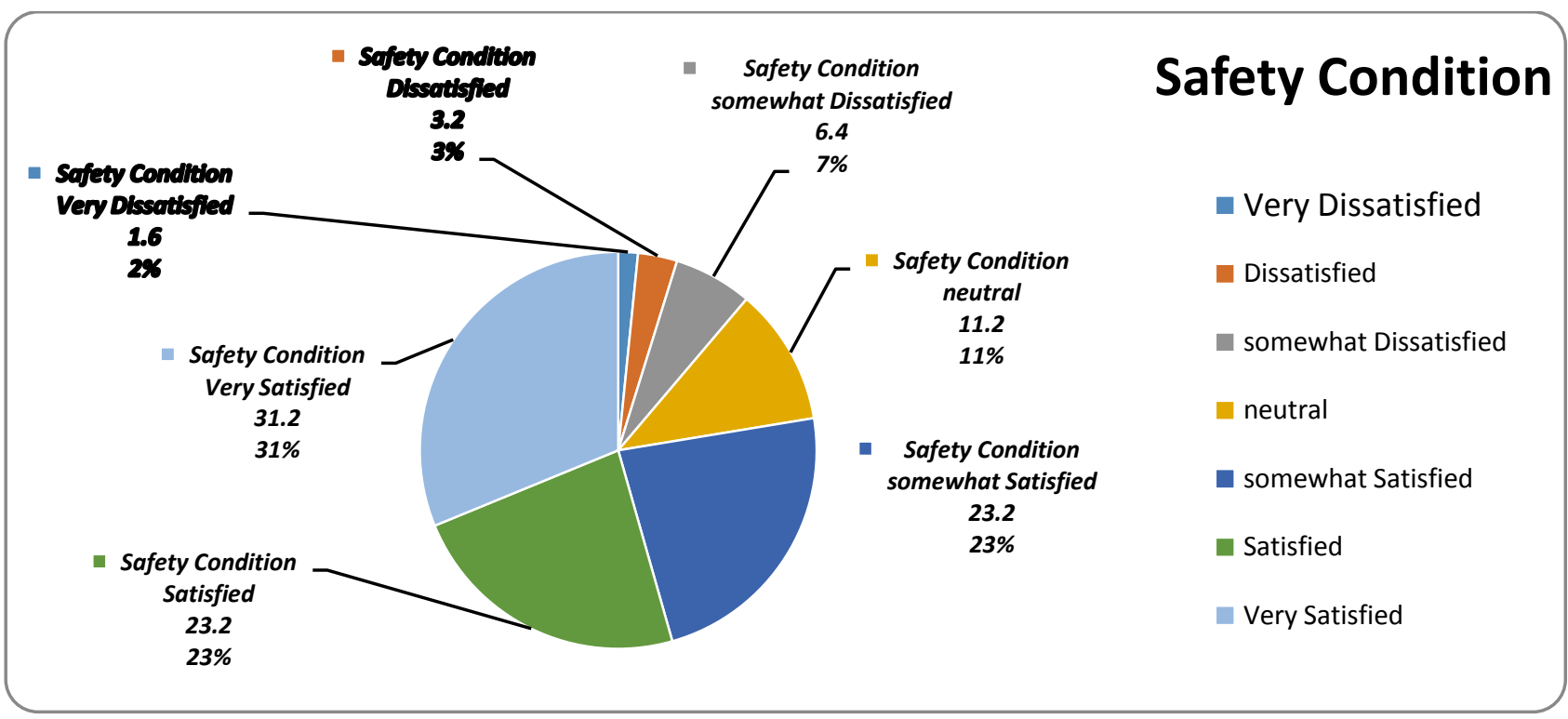

Fig: 9 Safe Working Environments

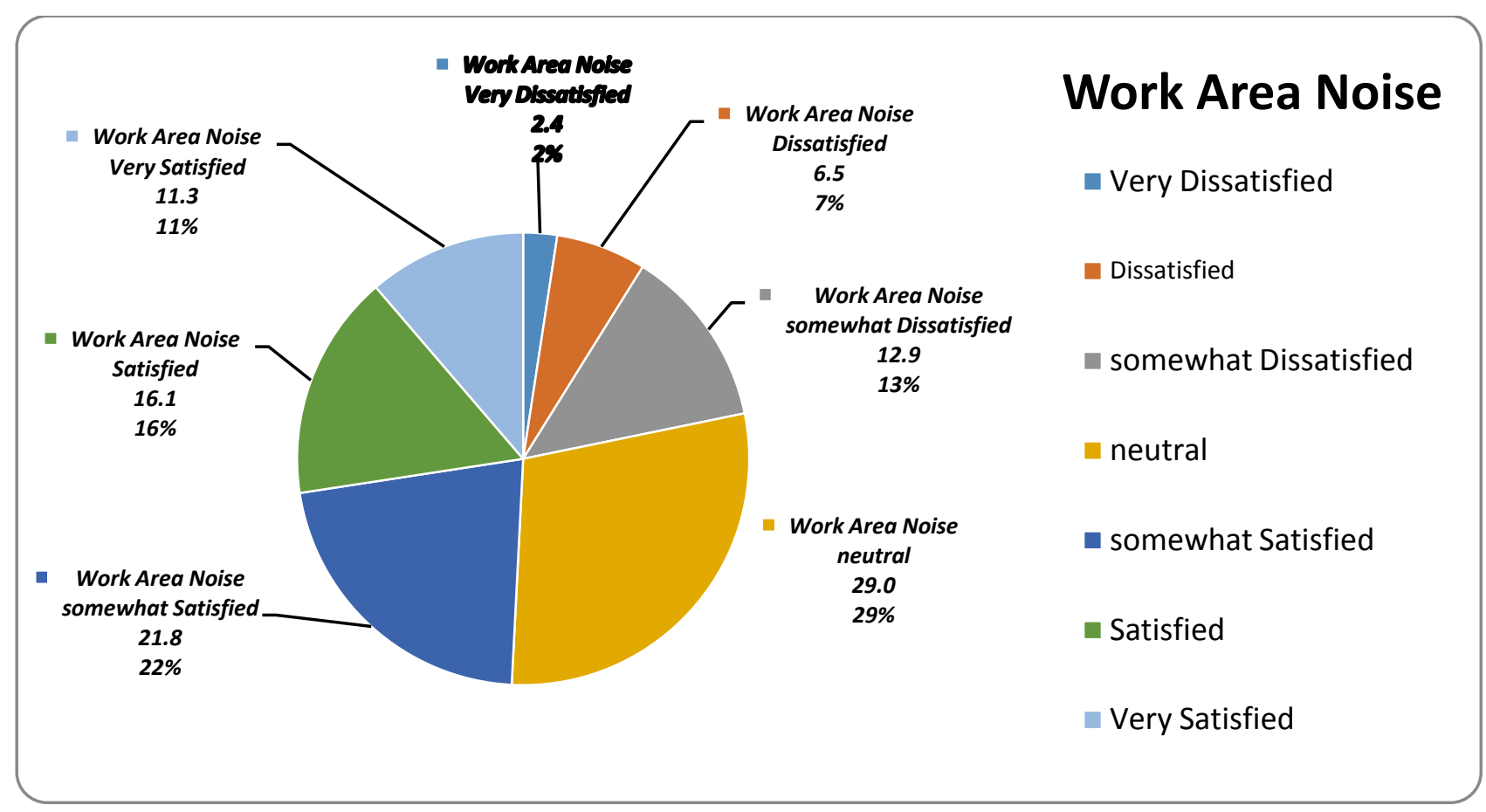

Fig: 10 Noise Pollution at Work 
The study also probed into overall working conditions for employees and several factors were looked into such as Safety Conditions (54\% satisfied) and Noise (27\% satisfied) where most of the employees do not seem to have a problem with the current conditions.

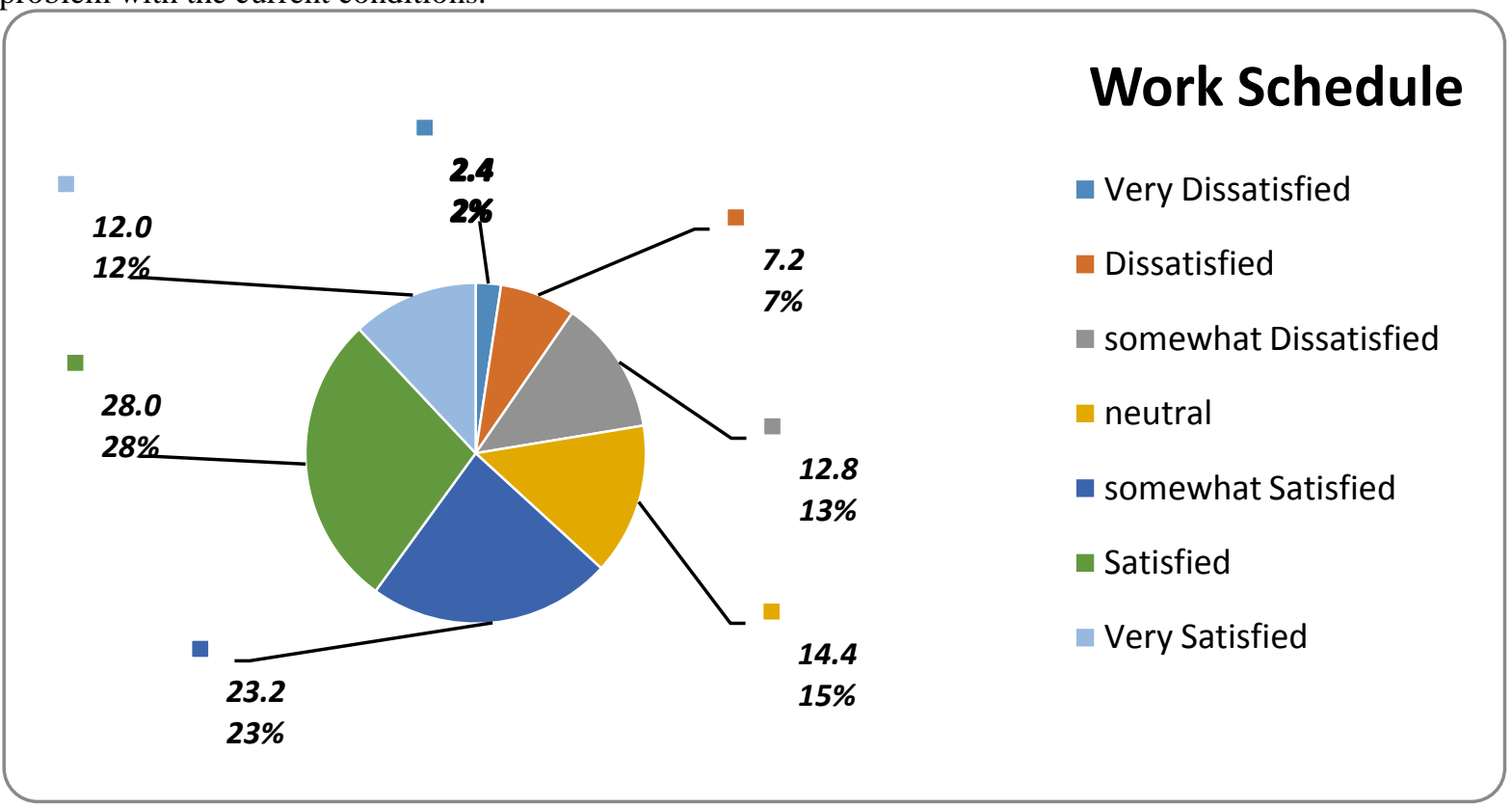

Fig: 11Satisfaction with Work Load

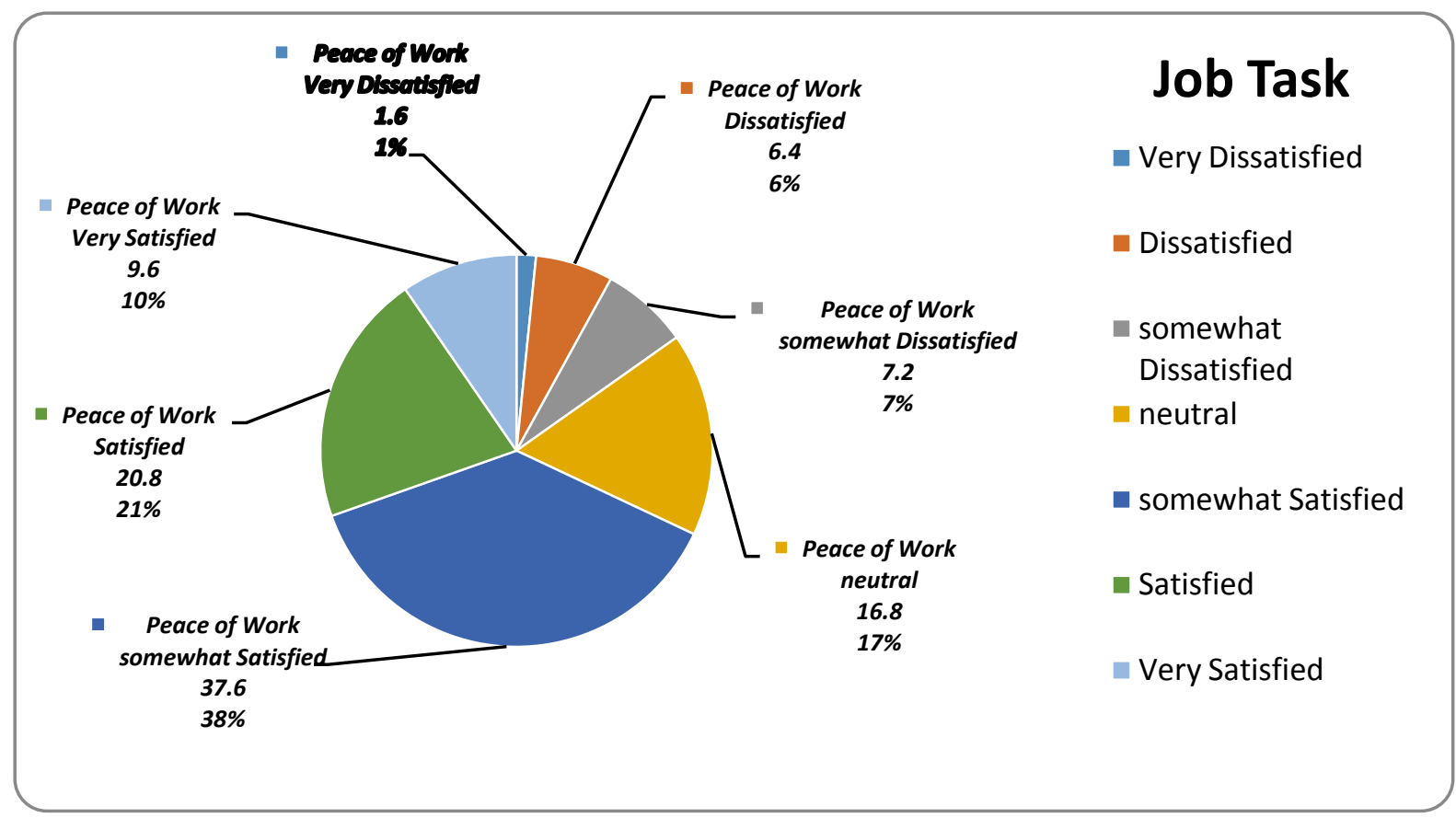

Fig: 12 Satisfactions with Job

Furthermore we find that factors such as Work Schedule and Jot Tanks majority of the employees are also satisfied with these issues $(40 \% \& 30 \%$ respectively). However there are a good number of workers $(22 \% \& 15 \%$ respectively) who are not at all happy with their current working schedules and the task they are given at hand. 
Many of the workers are also just barely happy with the current working conditions (23\% \& 38\% respectively) and could be converted into potential workers not looking to switch jobs if their needs are addressed by the management.

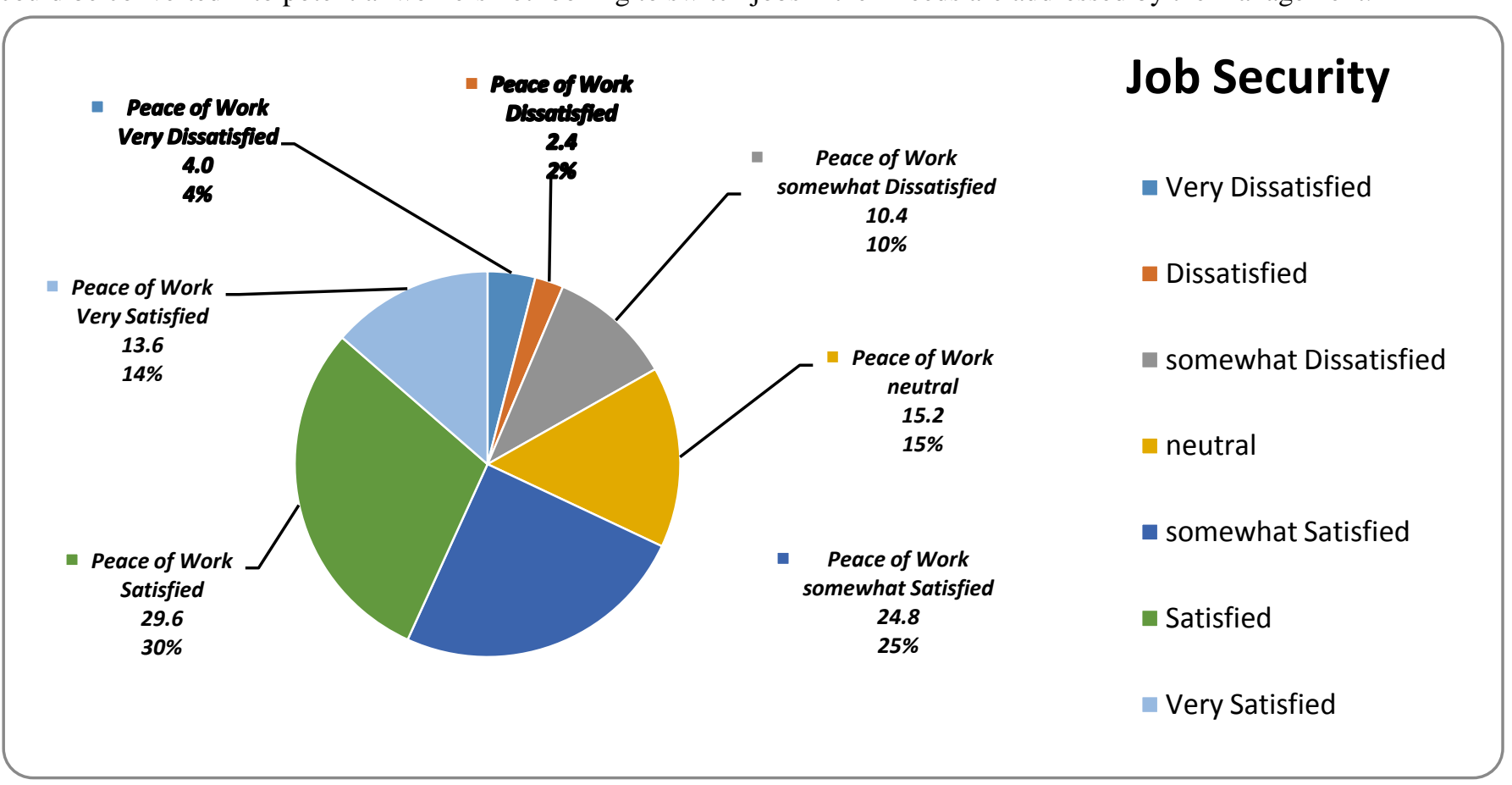

Fig: 13 Job Securities

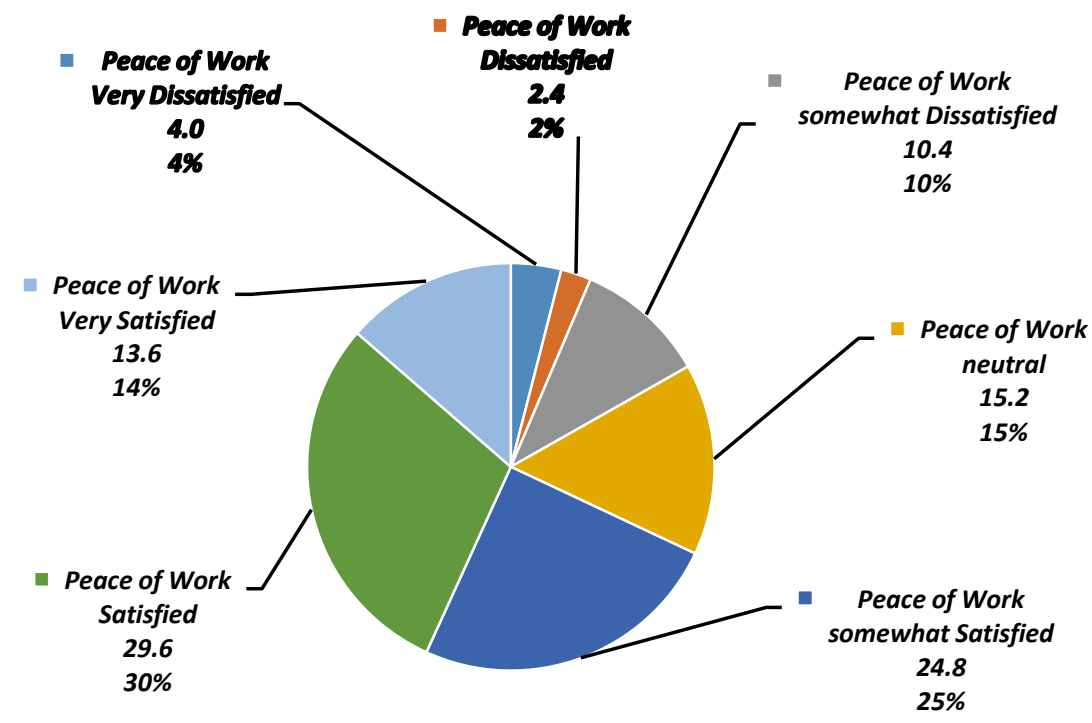

\section{Possibility of Promotion}

- Very Dissatisfied

- Dissatisfied

nomewhat Dissatisfied

neutral

n somewhat Satisfied

- Satisfied

very Satisfied

Fig: 14 Possibilities of Promotion

Again with factors such as Job Security and Promotion it was found that majority of the workers (43\% \& 43\% respectively) feel that they do have some job security and there is a possible chance of being promoted in their

(c) 2019, IJSMS

Page 52 
respective fields. However a group of employees are always left behind and not addressed properly where they feel that they do not have any job security or chance of being promoted ( $32 \% \& 32 \%$ respectively).

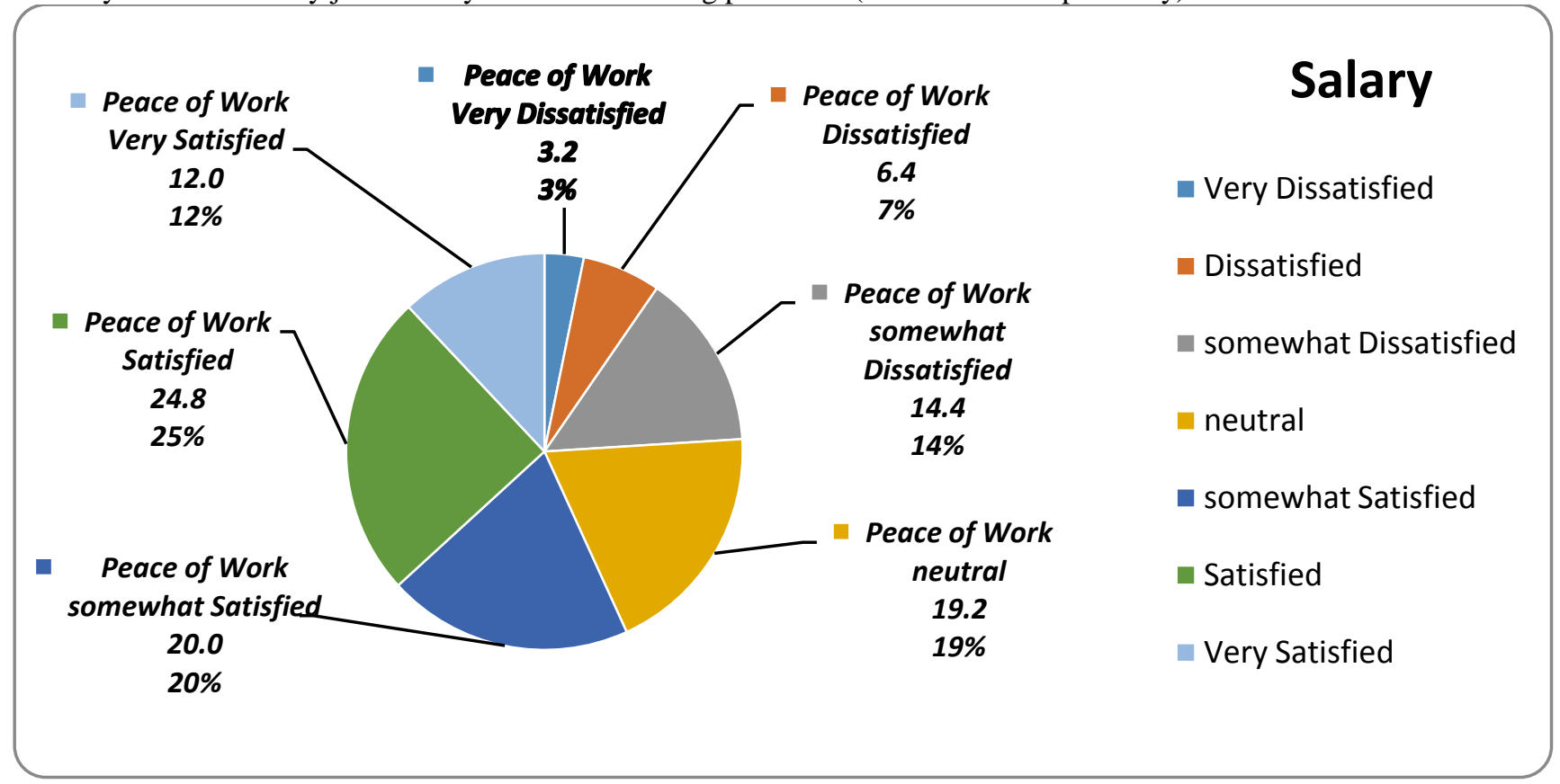

Fig: 15Satisfaction with Salary

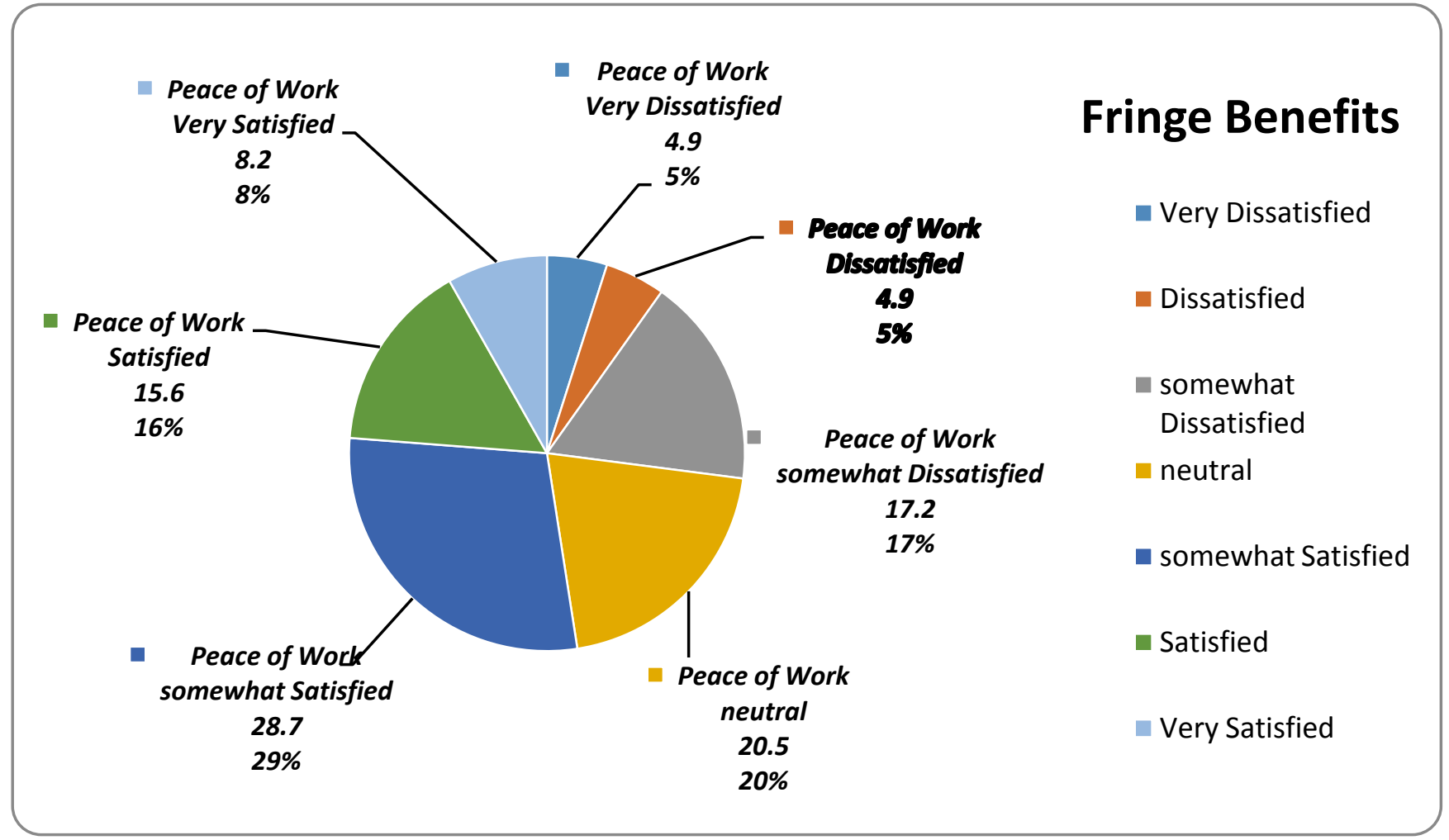

Fig: 16Satisfaction with Other Benefits 
Overall the study indicates that almost half of the respondents (43\% \& 48\% respectively) are not satisfied with the current salary they are receiving for their current post as most workers still feel that they are being overworked and underpaid by their employers. If a country is operating with almost half of their employees if various different industries feel that they are underpaid it is quite natural that there will grow a corporate culture where there will be a tendency for young workers to switch their jobs more frequently than warranted. This was previously discussed where we find that about a quarter of the workforce is constantly looking to switch their jobs if the opportunity arises. Again if this number keeps on rising where about half the workforce is not satisfied with their salary packages we will find a sharp increase in this job switching tendency which in no way can be a healthy practice both for the industries and the workforce as it will not only leave a bad impression on the workers' CVs, but will also gear up recruitment costs for the industries. As the study clearly indicates that the workforce is more dissatisfied with the fringe benefits and the overall benefit package rather than the salary itself, it goes to show that we have neglected to understand our worker's needs. Industries needs to focus on developing more flexible benefit packages which are more customized to individual needs rather than establishing salary scales across industries and various sectors. A package better suited to their needs, keeping in mind the fast expansion of Dhaka city itself and all its interconnected issues such as traffic jams, daily commuting of the workforce, having time to complete responsibilities on the home, giving time to family and friends and overall to maintain a better work life balance is becoming more and more important for the Bangladesh workforce. This is quickly becoming as issues that cannot be overlooked by industries any longer and has to be taken into account when developing future benefit packages of workers at all levels and across industries.

Table 1 Regression Score of Factor Analysis

\begin{tabular}{|c|c|c|c|c|c|c|c|}
\hline & & & $\begin{array}{l}\text { Sum of } \\
\text { Squares }\end{array}$ & Df & $\begin{array}{c}\text { Mean } \\
\text { Square }\end{array}$ & $\mathbf{F}$ & Sig. \\
\hline \multirow{3}{*}{$\begin{array}{l}\text { REGR factor } \\
\text { score } 1 \text { for } \\
\text { analysis } 1 *\end{array}$} & \multirow{3}{*}{$\begin{array}{l}\text { How old are } \\
\text { you? RANGE }\end{array}$} & Between Groups (Combined) & 9.983 & 4 & 2.496 & \multirow[t]{3}{*}{3.104} & \multirow[t]{3}{*}{.018} \\
\hline & & Within Groups & 94.081 & 117 & .804 & & \\
\hline & & Total & 104.064 & 121 & & & \\
\hline \multirow{3}{*}{$\begin{array}{l}\text { REGR factor } \\
\text { score } 1 \text { for } \\
\text { analysis } 1 *\end{array}$} & \multirow[t]{3}{*}{ Gender } & Between Groups $\quad$ (Combined) & .117 & 1 & .117 & \multirow[t]{3}{*}{.135} & \multirow[t]{3}{*}{.714} \\
\hline & & Within Groups & 103.812 & 119 & .872 & & \\
\hline & & Total & 103.929 & 120 & & & \\
\hline \multirow{3}{*}{$\begin{array}{l}\text { REGR factor } \\
\text { score } 1 \text { for } \\
\text { analysis } 1 *\end{array}$} & \multirow[t]{3}{*}{ Marital Status } & Between Groups (Combined) & 6.304 & 1 & 6.304 & \multirow[t]{3}{*}{7.739} & \multirow[t]{3}{*}{.006} \\
\hline & & Within Groups & 97.759 & 120 & .815 & & \\
\hline & & Total & 104.064 & 121 & & & \\
\hline \multirow{3}{*}{$\begin{array}{l}\text { REGR factor } \\
\text { score } 1 \text { for } \\
\text { analysis } 1 *\end{array}$} & \multirow{3}{*}{$\begin{array}{l}\text { Highest } \\
\text { Education }\end{array}$} & Between Groups (Combined) & 2.152 & 3 & .717 & \multirow[t]{3}{*}{.822} & \multirow[t]{3}{*}{.484} \\
\hline & & Within Groups & 101.250 & 116 & .873 & & \\
\hline & & Total & 103.402 & 119 & & & \\
\hline \multirow{3}{*}{$\begin{array}{l}\text { REGR factor } \\
\text { score } 1 \text { for } \\
\text { analysis } 1 *\end{array}$} & \multirow{3}{*}{$\begin{array}{l}\text { Job Position } \\
\text { NEW CAT }\end{array}$} & Between Groups $\quad$ (Combined) & 3.733 & $\overline{4}$ & .933 & \multirow[t]{3}{*}{1.029} & \multirow[t]{3}{*}{.413} \\
\hline & & Within Groups & 20.857 & 23 & .907 & & \\
\hline & & Total & 24.589 & 27 & & & \\
\hline \multirow{3}{*}{$\begin{array}{l}\text { REGR factor } \\
\text { score } 1 \text { for } \\
\text { analysis } 1 *\end{array}$} & \multirow{3}{*}{$\begin{array}{l}\text { Type of Industry } \\
\text { (Specific) NEW } \\
\text { CAT }\end{array}$} & Between Groups (Combined) & 3.844 & 5 & .769 & \multirow[t]{3}{*}{.854} & \multirow[t]{3}{*}{.529} \\
\hline & & Within Groups & 17.106 & 19 & .900 & & \\
\hline & & Total & 20.951 & 24 & & & \\
\hline
\end{tabular}




\section{DISCUSSION}

Comparing the Regressing factor against the Demographic Factors it was seen that Age and Marital Status are significant factors $(0.018 \& 0.006$ respectively).This is indicative of local cultural presumptions that people who are in the older age brackets and have a family to maintain seems content with their present jobs and are less likely to switch drastically.

Again looking at the Turnover prospects we find that the turnover ratio of the older employees is better than that of the younger employees. This is indicative of common practices where the younger employee with no family responsibilities over their shoulders seems to have a higher job switching frequency.

\section{CONCLUSION}

Although a satisfactory salary package may help to reduce the turnover of an organization, it is not the only solution for the authorities. The study finds that in most cases employees do not stay in an organization only because of their salary package, but he or she may also stay for many other reasons like rearranging employees good stream relations, better working environment, it is not the only solution for preferable job location etc. The study can alert the top management that if they give more attention to the retirement benefits, job security and financial crises then they can reduce the level of turnover of the professional employees who could become a core asset for the organization. However, the study indicates that the older, and more matured employees with a family, if coupled with an effective fringe benefit package which supports a healthy work life balance will always stay loyal with their organization.

\section{ACKNOWLEDGMENT}

The preferred spelling of the word "acknowledgment" in American English is without an "e" after the "g." Use the singular heading even if you have many acknowledgments. Avoid expressions such as "One of us (J.Q.A.) would like to thank ... ." Instead, write "J. Q. Author thanks ... ." Sponsor and financial support acknowledgments are placed in the unnumbered footnote on the first page.

\section{REFERENCES}

[1] Abassi SM, Hollman KW (2000). Turnover: the real bottom line. Public Personnel Management, 2 (3):333-342.

[2] Alexander J, Bloom J, Nuchols B (1994). Nursing turnover and hospital efficiency: an Organization-level analysis. Industrial Relations, 33 (4):505-520.

[3] Amabile M (1997). Motivating creativity in organizations: On doing what you love and loving what you do. California Management Review, 40:39-58.

[4] Black, Gomes and Edward, Kennedy (2000).Procedural Fairness, Outcome Favorability, and Judgments of an Authority's Responsibility. Journal of Applied Psychology, 92(6):1657-1671.

[5] Carsten, J. M., \& Spector, P. E. (1987). Unemployment, job satisfaction, and employee turnover: A meta-analytic test of the Muchinsky model. Journal of Applied psychology, 72(3), 374.

[6] Catherine M Gustafson (2002). Staff turnover: Retention".International Journal of Contemporary Hospitality Management, 14 (3): $106-110$.

[7] Costly, Hongkrailert, N., Sermsri, S.( 1987). Job Satisfaction among nurses in AcehTimer district Mangrove Aceh Darussalam province Indonesia. Health Development Journal, 6(1):155.

[8] Cotton J, Tuttle J (1986). Employee turnover: A meta-analysis and review with implication for research. Acad. Manag. Rev. 11(1):55-70.

[9] Dess GD, Shaw JD (2001). Voluntary turnover, social capital, and organizational performance, Academy of Management Review, 26(3):446-56.

[10] Gandolfi F (2008). Fundamentals of Human Resources Management (HRM), Lulu Publications.http://www.lulu.com/ content/2204914.

[11] Griffith, R. W., \&Hom, P. W. (2004).Innovative theory and empirical research on employee turnover.IAP.

[12] Griffeth RW, Hom PW, Gaertner S (2000). A meta-analysis of antecedents and correlates of employee turnover: Update, moderator tests, and research implications for the next millennium. Journal of Management, 26:463-488.

[13] Hatton C, Emerson E (1998). Organizational Predictors of Staff Stress, Satisfaction, and Intended Turnover in Services for People with Multiple Disabilities.Mental Retardation, 31(6):388-399.

(C) 2019, IJSMS

Page 55 
[14] Hezberg F (1973). Motivation: Management of success. Elkgrove Village, Illinois: Advanced System Inc.

[15] Hogan JJ (1992). "Turnover and what to do about it", The Cornell HRA Quarterly. 33 (1):40-45.

[16] Hoppock (2005).Job satisfaction. The career advancement prospects of managers and professionals. Decision Sciences, 23(2):478-500.

[17] Idson TL, Feaster DJ (1990). A selectivity model of employer-size wage differentials. Journal of Labor Economics, 8: 99-122.

[18] Johnson RW (2004). Trends in job demands among older workers: 1992-2002.Monthly Labor Review, 127(7):48-56.

[19] Kramer, M. W., Callister, R. R., \& Turban, D. B. (1995).Information- receiving and information- giving during job transitions.Western Journal of Communication, 59(2), 151-170.

[20] Kevin MM, Joan LC, Adrian JW (2004). Organizational change and employee turnover.Personnel Review, 33 (2):161-166.

[21] Koh HC, Goh CT (1995).An analysis of the factors affecting the turnover intention of non managerial clerical staff: A Singapore study. International Journal of Human Resource Management, 6(1).

[22] Labov B (1997). Inspiring employees the easy way.Incentive, 171(10):114-18.

[23] Magner, N., Welker, R and Johnson, G. (1996).The interactive effects of participation and outcome favorability in performance appraisal on turnover intentions and evaluations of supervisors.Journal of occupational and organizational Psychology, 69: 135-143.

[24] Malone TW (1997). Is empowerment just a fad? Control, decision making, and IT.Sloan Management Review, 38 (2): 23-9.

[25] Mano Rita -Negrin, Shay S Tzafrir (2004).Job search modes and Turnover.Career development international, (5): 442-446.

[26] Maslow, W.H.(1970): Employee Turnover: Causes, Consequences and Control. Addison-Wesley Reading, 1982

[27] Meaghan Stovel, Nick Bontis (2002), Voluntary turnover: knowledge management-friend or foe?Journal of Intellectual Capability, 3 (3): 303-322

[28] Mishra, A. K., \&Spreitzer, G. M. (1998). Explaining how survivors respond to downsizing: The roles of trust, empowerment, justice, and work redesign. Academy of management Review, 23(3), 567-588.

[29] Moorman RH (1991), Relationship between Organizational Justice and Organizational Citizenship Behaviors: Do Fairness Perceptions Influence Employee Citizenship?Journal of Applied Psychology, 76:845-855.

[30] Phillips, J. D. (1990). The price tag on turnover. Personnel Journal, 69(12), 58-61.

[31] Price JL, Mueller CW (1986). A Causal Model of Turnover for Nurses. Academy of Management Journal, 24:543-565.

[32] Price JL, Mueller CW (1986). Absenteeism and Turnover of Hospital Employees, Greenwich, CT: JAI Press.

[33] Price JL, Mueller CW (2001). Absenteeism and Turnover of Hospital Employees, Greenwich, CT: JAI Press.

[34] Rankin, N (2006). Benchmarking Labor Turnover.IRS Employment Review, No 842, 3 March; 2006, p. 42-48.

[35] Shaw, J. D., Delery, J. E., Jenkins, G. D. Jr., and Gupta, N. (1998).An organization-level analysis of voluntary and involuntary turnover.Academy of Management Journal, 41(5), 511-525.

[36] Staw BM (1980). The consequences of turnover.Journal of Occupational Behavior, 1:253-273.

[37] Shamsuzzoha AHM, Shumon Md. RezaulHasan (2006). Employee Turnover-a Study of its Causes and Effects to Different Industries in Bangladesh.Journal of Applied Psychology, 2006, 72: 382-386.

[38] Tett RP, Meyer JP (1993). Job Satisfaction, Organizational Commitment, Turnover Intention, and Turnover: Path Analyses Based on Metaanalytic Findings. Personal Psychology, 46:259-293.

[39] Trevor, C. O. (2001). Interactions among actual ease-of-movement determinants and job satisfaction in the prediction of voluntary turnover.Academy of management journal, 44(4), 621-638.

[40] Weisberg, J., \&Kirschenbaum, A. (1993).A model of voluntary turnover among hospital CEOS.Hospital and Health Service Administrative, $40(3), 362-385$.

[41] Williams LJ, Hazer JT (1986). Antecedents and consequences of satisfaction and commitment in turnover models: a reanalysis using latent variable structural equation methods. Journal of AppliedPsychology, 71(2):219-231. 